\title{
Vozes à infância silenciada: impactos da hospitalização e hemodiálise à escolarização de crianças com doença renal crônica
}

\author{
Voices to silent infance: impacts of hospitalization and hemodialysis on \\ schooling of children with chronic kidney disease
}

Voces a la infancia silenciada: impactos de la hospitalización y hemodiálisis a la escolarización de niños con enfermedad renal crónica

Karina Cristina Rabelo Simões

Mestra pela Universidade Federal do Maranhão, São Luís, Maranhão, Brasil. karinarabelo.simoes@gmail.com

ORCID - https://orcid.org/0000-0002-8385-3986

Silvana Maria Moura da Silva

Professora doutora na Universidade Federal do Maranhão, São Luís, Maranhão, Brasil.

silvana.moura@ufma.br

ORCID - https://orcid.org/0000-0001-9331-6319

Maria da Piedade Resende da Costa

Professora doutora na Universidade Federal de São Carlos, São Carlos, São Paulo, Brasil.

piedade@ufscar.br

ORCID - https://orcid.org/0000-0002-7420-5602

Recebido em 18 de maio de 2020

Aprovado em 6 de agosto de 2020

Publicado em 26 de outubro de 2020

\section{RESUMO}

Os impactos provenientes da hospitalização e/ou atendimento ambulatorial hemodialítico ao processo de escolarização de crianças com insuficiência renal crônica podem ser comprometedores ao desenvolvimento infantil, causando às mesmas rupturas contextuais, mudanças na vida cotidiana, impedimentos na continuidade aos estudos e à rotina anterior vivenciada. Buscou-se analisar os impactos da hospitalização e/ou atendimento ambulatorial hemodialítico ao processo de escolarização de crianças com insuficiência renal crônica. Tratou-se de uma pesquisa do tipo quanti-qualitativa, descritiva, sob a forma de múltiplos casos. Os participantes foram 10 crianças com insuficiência renal crônica, faixas etárias variando entre 8 e12 anos de idade, inseridas em três grupos contextuais: três crianças hospitalizadas, seis em atendimento ambulatorial hemodialítico e uma submetida aos dois processos hospitalares, em duas unidades de atendimento de um hospital público federal em São Luís. Foram aplicadas individualmente com elas, entrevistas semiestruturadas, envolvendo história interativa, livro autobiográfico e caixa dos desejos. Os maiores impactos da hospitalização e/ou atendimento ambulatorial hemodialítico ao processo de escolarização foram: atrasos escolares e comprometimentos futuros pela impossibilidade de frequência escolar (60\%); perda do vínculo escolar pela distância entre hospital e escola (20\%); ausência de recursos apropriados à escolarização no hospital (10\%) e dificuldades de realizar matrícula em escola próxima de casa (10\%). 
http://dx.doi.org/10.5902/1984686X44360

Concluiu-se que os maiores impactos à escolarização foram manifestados pelas crianças em tratamento hemodialítico, por ser um processo contínuo, imprevisível e indeterminado, demandando maiores privações do contexto escolar ou mesmo ausências, variando de cinco meses a quatro anos, ocasionando maiores déficits escolares e comprometendo a vida escolar.

Palavras-chave: Hospitalização; escolarização; insuficiência renal crônica.

\section{ABSTRACT}

The impacts of hospitalization and/or hemodialysis outpatient care to the schooling process of children with chronic renal failure may be compromising the child's development, causing the same contextual ruptures, changes in daily life, impediments to the continuity of studies and to the previous experienced routine. We tried to analyze the impacts of hospitalization and/or hemodialysis outpatient care to the schooling process of children with chronic renal failure. It was a quanti-qualitative, descriptive survey in the form of multiple cases. The participants were 10 children with chronic renal failure, from 8 to 12 years old, in three contextual groups: three hospitalized children, six in hemodialysis outpatient care and one submitted to the two hospital processes, in two care units of a federal public hospital in São Luís. Semi-structured interviews involving interactive history, autobiographical book and wish box were applied individually with them. The greatest impacts of hospitalization and/or hemodialysis outpatient care on the schooling process were: school delays and future commitments due to the impossibility of school attendance $(60 \%)$; loss of school bond due to the distance between hospital and school $(20 \%)$; lack of appropriate resources for schooling in the hospital (10\%) and difficulties to enroll in a school close to home $(10 \%)$. It was concluded that the greatest impacts to schooling were manifested by children under hemodialysis treatment because it is a continuous, unpredictable and undetermined process, demanding greater deprivation of the school context or even absences, ranging from five months to four years, causing greater school deficits and compromising school life.

Keywords: Hospitalization; schooling; chronic renal failure.

\section{RESUMEN}

Los impactos provenientes de la hospitalización y/o atendimiento de ambulatorio de hemodiálisis al proceso de escolarización de niños con insuficiencia renal crónica pueden ser comprometedoras al desarrollo infantil, causándoles rupturas contextuales, cambios en la vida cotidiana, impedimentos en la continuidad a los estudios y rutina anterior vivenciada. Se buscó analizar los impactos de la hospitalización y/o atendimiento de ambulatorio de hemodiálisis al proceso de escolarización de niños con insuficiencia renal crónica. Se trató de una investigación de tipo cuanti-cualitativa, descriptiva, bajo la forma de múltiplos casos. Los participantes fueran 10 niños com insuficiencia renal crónica, rango de edad variando entre 8 a 12 años insertadas en tres grupos contextuales: tres niños hospitalizados, seis en atendimiento de ambulatorio de hemodiálisis y una sometida a los dos procesos hospitalarios, en dos unidades de atendimiento de un hospital público federal en la ciudad de São Luís. Fueron aplicados individualmente a los participantes, entrevistas semiestructuradas, envolviendo historia interactiva, libro autobiográfico y caja de los deseos. Los mayores impactos de la hospitalización y/o atendimiento de ambulatorio de hemodiálisis al proceso de escolarización fueron: atrasos escolares y comprometimientos futuros por la imposibilidad de frecuencia escolar (60\%); pérdida del vínculo escolar por la distancia entre hospital y escuela (20\%); ausencia de recursos apropiados a la escolarización en el hospital (10\%) y dificultades de realizar matrícula en escuela cerca de 
la casa (10\%). Se concluyó que los mayores impactos a la escolarización fueron manifestados por los niños en tratamiento de hemodiálisis por ser un proceso continuo, imprevisible e indeterminado, demandando mayores privaciones del contexto escolar o ausencias, variando entre cinco meses a cuatro años, ocasionando mayores déficits escolares y comprometiendo la vida escolar.

Palabras clave: Hospitalización; escolarización; insuficiencia renal crónica.

\section{Introdução}

Os impactos provenientes da hospitalização e/ou atendimento ambulatorial hemodialítico ao processo de escolarização de crianças com insuficiência renal crônica podem ser comprometedores ao desenvolvimento infantil, na medida em que as limitações e submissões ocasionadas por uma patologia causam o impedimento ao retorno escolar, consonante à realidade vivenciada por cada uma. A cronicidade da patologia faz com que a criança dependa do contexto hospitalar por longos períodos de tempo para tratamento da saúde e, assim, as defasagens escolares tendem a intensificar-se (PENNAFORT; QUEIROZ; JORGE, 2012).

As doenças crônicas são aquelas que não possuem cura, porém exigem controle clínico permanente, devido às suas consequentes limitações e/ou incapacitações em graus permanentes, comprometendo assim a rotina de vida de crianças, jovens e adultos (GROSSMAN, 2007).

A origem de uma doença crônica é diversificada e pode acontecer em várias fases da vida. De acordo com Grossman (2007), pode manifestar-se na infância ou em qualquer fase de desenvolvimento. No entanto, optar pela insuficiência renal crônica (IRC), nesta pesquisa, ocorreu pela debilitação e maior dependência que ocasiona, comprometendo a qualidade de vida da pessoa acometida por essa enfermidade.

Como afirmou Frota et al. (2010, p. 528), em relação às implicações da insuficiência renal crônica, "na realidade infantil, suas repercussões são ainda mais graves, pois requerem atenção diferenciada. A criança passa por alteração relacionada ao crescimento e desenvolvimento".

Vieira, Dupas e Ferreira (2009) ressaltaram que as condições clínicas e dependência do espaço hospitalar exigem da criança com insuficiência renal crônica um controle à longo prazo, que nem sempre são incapacitantes, mas provocam limitações de suas atividades rotineiras, devido às mudanças no estilo e qualidade de vida, que podem gerar instabilidade 
http://dx.doi.org/10.5902/1984686X44360

emocional em toda a família, bem como comprometimentos no desenvolvimento físico, emocional e desajustes psicológicos na criança, decorrentes do tratamento.

A durabilidade e o risco de complicações da insuficiência renal crônica conduzem ao controle e cuidados permanentes para que se evitem possíveis sequelas. Suscetíveis a estes fatores as crianças sofrem muitas privações e limitações pelas exigências de seus tratamentos.

Sendo assim, a sujeição das crianças às hospitalizações reincidentes por longos períodos e a necessidade de tratamento ambulatorial de hemodiálise implicaram em transtornos psicossociais pelos constantes deslocamentos da cidade de origem, localizada no interior do Maranhão para a capital, bem como impossibilitaram a ida dessas crianças à escola, dificultando o processo de escolarização delas.

Ressalta-se que a localização geográfica do grupo estudado, cuja residência fixada em cidades do interior maranhense, obrigava o deslocamento das crianças com IRC para a capital São Luís, tendo de realizar deslocamentos com distâncias que variaram de 213 km a 2.965 km. Além dessa realidade, algumas crianças oriundas de cidades mais distantes precisaram mudar-se para São Luís, devido aos gastos ocasionados pelos deslocamentos constantes. Considerando essa realidade, outro aspecto a ser enfatizado é a ausência de classe hospitalar no local selecionado para a pesquisa. Essa ausência impossibilitava a articulação entre hospital e escola de origem para a manutenção do vínculo escolar, objetivando suprir as necessidades educacionais infantis, diante dos impactos causados pela hospitalização e/ou pelo atendimento ambulatorial hemodialítico.

Ressalta-se que os impactos ao processo de escolarização podem ser diversos, pela distância de casa, da família e do espaço escolar, mostrando a realidade de uma infância que se diferencia contextualmente das demais (SIMÕES, 2016).

Sabe-se que a educação em sociedade é considerada "direito de todos e dever do Estado" (BRASIL, [1988], não paginado). Nesse sentido, considerando-a como um direito pleno, tornam-se imprescindíveis meios para assegurá-la e, a priori, tem-se a legislação. Assim, documentos com origem nacional e internacional, objetivando prezar pela universalização da educação, amparam e promovem a efetivação do acesso a esse direito, dentro do possível (SIMÕES, 2016).

Como discorreu Rabelo (2014, p. 63) "a educação formal enfrenta mudanças de acordo com a mobilidade da sociedade enquanto novos espaços educacionais aparecem no cenário educativo dando visibilidade à educação não escolar". Surgem, nessa 
http://dx.doi.org/10.5902/1984686X44360

mobilidade da sociedade, novos atores sociais, que necessitam de um olhar singular, de acordo com suas próprias sutilezas. Esses atores sempre existiram no contexto histórico social, porém, pouco foram vistos e escutados (SIMÕES, 2016).

No entanto, o fenômeno da educação e sua efetividade perpassam por longos caminhos, os quais dificultam o seu alcance a todos. As necessidades educacionais são manifestadas nos mais diversos contextos, sendo estes formais ou não formais. Assim, compreende-se que a educação deve estar presente em todos os locais em que se faz necessária, garantindo o direito de aprender (SIMÕES, 2016).

Nesse sentido, a escola pode constituir-se em um espaço que promove a democracia, inclusão e acesso à educação a todos. De acordo com Drago (2011, p.19), “a escola, para grande parte das crianças brasileiras é o único espaço de acesso aos conhecimentos universais e sistematizados socialmente"

Considerada a escola como espaço único de acesso ao conhecimento, verifica-se, neste processo, a promoção da segregação, a partir do momento em que surgem, em sociedade, grupos sem possibilidade de deslocamento à escola, ou precisando ausentarse do espaço escolar. Essa impossibilidade de deslocamento à escola ocorre em função dos tratamentos de saúde, os quais ocasionam limitações físicas. Como enfatizado por Drago (2011), são situações desafiadoras que ultrapassam a noção espaço-temporal; que restringem esse acesso à escola e comprometem a garantia do direito à educação para todos.

O olhar volta-se em especial às crianças com patologia crônica, pois demandam longo período de hospitalização, internações recorrentes ou atendimento ambulatorial hemodialítico constante. Todos esses fatores são responsáveis pela presença limitada ou ausência dessas crianças no ambiente educacional e, consequentemente, pelos impactos ao processo de escolarização das mesmas. Assim, destaca-se como protagonistas desta pesquisa, a criança com insuficiência renal crônica, sendo esta hospitalizada e/ou em atendimento ambulatorial hemodialítico (SIMÕES, 2016).

Neste ínterim, parte-se da ideologia e do reconhecimento de que a infância é socialmente construída e reconstruída em relação a uma multiplicidade complexa de dimensões, como tempo, espaço, idade, gênero, etnia, classe social, etc (BARBOSA; DELGADO; TOMÁS, 2016). A pesquisa parte da concepção de que existem diversas infâncias, sendo estas contextualizadas diferenciadamente e construídas socialmente, pois 
http://dx.doi.org/10.5902/1984686X44360

exigem da pessoa comportamentos correspondentes e submissos ao ambiente de inserção, a exemplo, aquelas que acontecem no processo de hospitalização.

Para Pérez-Ramos (2008, p. 112), "a hospitalização para a criança altera, significativamente o seu dia-a-dia e seu ambiente de convivência, correndo o risco de comprometer expressivamente o seu desenvolvimento". Se o tempo de permanência hospitalar é prolongado, essas limitações tornam-se agravadas e consequenciais, causando prejuízos à infância, ao seu desenvolvimento e, especificamente, ao seu processo de escolarização (SIMÕES, 2016).

Desta forma, a criança é estimulada e constituída por fatores essenciais à sua formação, enquanto ser humano. Na escola, em parceria com a família, a criança é oportunizada a maiores condições de desenvolvimento saudável (SIMÕES, 2016). Para Matos e Mugiatti (2011, p. 27), "a etapa escolar representa o próprio desenvolvimento de potencialidades, da personalidade e da capacidade de comunicação". No entanto, a hospitalização e, consequentemente, a interrupção do processo de escolarização podem ocasionar graves problemas de natureza psicopatológica, como traumas e alterações de conduta diante de tais limitações (GIL, 2010).

Os comprometimentos educacionais e sociais tornaram-se visíveis e foram contemplados em leis, que asseguram o direito à educação a crianças e adolescentes em processo de hospitalização e/ou atendimentos ambulatoriais múltiplos, a exemplo, a Resolução de no 41 de 1995, dos Direitos da Criança Hospitalizada (CONSELHO NACIONAL DOS DIREITOS DA CRIANÇA E DO ADOLESCENTE, 1995). Esse documento apresentou o perfil dos educandos com necessidades educacionais especiais e dos que apresentem dificuldades de acompanhamento curricular pelas condições e limitações impostas por tratamento de saúde, carecendo do atendimento pedagógico-educacional hospitalar (SIMÕES, 2016).

A criança, enquanto paciente no hospital, é acolhida na perspectiva da cura e a atenção está voltada, predominantemente, ao seu estado clínico. Essa atenção, muitas vezes, centralizada apenas no cuidar e na doença ocasiona o distanciamento por parte das crianças de necessidades próprias da infância, como o processo de escolarização e o vínculo familiar, que sofrem rupturas de graus variados, tornando-se até permanentes (SIMÕES, 2016). Tais rupturas provocam impactos na vida e no processo de escolarização de crianças com insuficiência renal crônica, constatadas em diversos estudos como Vieira 
http://dx.doi.org/10.5902/1984686X44360

e Lima (2002), Piccinini et al. (2003), Vieira, Dupas e Ferreira (2009), Pennafort (2010), Amorim (2014), dentre outros.

Conforme $\circ \S 1^{\circ}$ do Art. $1^{\circ}$ do Decreto $\mathrm{n}^{\circ}$ 7.611, de 17 de novembro de 2011, considera-se público-alvo da educação especial: pessoas com deficiência, com transtornos globais de desenvolvimento e com altas habilidades ou superdotação (BRASIL, 2011). A Política Nacional de Educação de Educação Especial na Perspectiva da Educação Inclusiva (BRASIL, 2008), complementando essas considerações, delimita que o mesmo público definido pela Resolução № 4, de 2009, deve ter acesso às escolas regulares e ao atendimento educacional especializado, complementar e ou suplementar ao ensino comum (BRASIL, 2009).

O público-alvo da Educação Especial não inclui as crianças em situação de agravamento das condições de saúde, mas as mesmas têm o direito de ser inseridas integralmente, e não condicionalmente, no atendimento educacional hospitalar, por meio da classe hospitalar - normalmente entendido como um serviço de atendimento especializado da educação especial -, para que não percam o vínculo com a escola de origem, assim como para evitar maiores atrasos em seu processo educativo, reprovações e até mesmo a evasão escolar, situações essas bastante comuns em crianças com IRC submetidas a hospitalizações e/ou atendimentos ambulatoriais hemodialíticos.

No caso de crianças em situação de agravamento das condições de saúde, foi aprovada a Lei n⒔716, de 2018, que definiu o acompanhamento curricular durante 0 tratamento de saúde como espaço de direito, de maneira que possam estar inseridas integralmente, e não condicionalmente, no atendimento educacional hospitalar (BRASIL, 2018). Este documento, também, alterou a Lei de Diretrizes e Bases da Educação Nacional, que rege a educação brasileira. Assim, o Art. 4ํㅡ da lei assegura:

o atendimento educacional, durante o período de internação, ao aluno da educação básica internado para tratamento de saúde em regime hospitalar ou domiciliar, por tempo prolongado, conforme dispuser o Poder Público em regulamento, na esfera de sua competência federativa. (BRASIL, 2018, p. não paginado)

Assim, a efetivação do direito educacional à criança em tratamento de saúde é concretizada legalmente, apontando-se a necessidade da sistematização de classes hospitalares em ambientes de saúde, com atendimentos pedagógicos que proporcionem a continuidade dos vínculos escolares, em articulação com as escolas de origem desses alunos 
http://dx.doi.org/10.5902/1984686X44360

Porém, apesar de ser uma lei de extrema relevância na conquista de direitos desse público, não contempla aquelas crianças que não estão necessariamente em regime de hospitalização, mas em atendimentos ambulatoriais e que também sofrem muitos impactos no processo de escolarização, a exemplo, as crianças com insuficiência renal crônica em tratamento ambulatorial hemodialítico, também abordadas nesta pesquisa.

Esta pesquisa enfatiza a realidade hospitalar e dos atendimentos ambulatoriais, em consonância com a privação de dois lugares elementares à educação e ao desenvolvimento infantil: a casa/família e a escola. Considerando que a educação e a família são imprescindíveis ao desenvolvimento infantil, apresenta-se como questão central à luz do exposto: Quais os impactos da hospitalização e/ou do atendimento ambulatorial hemodialítico ao processo de escolarização de crianças com insuficiência renal crônica?

Dessa maneira, o presente trabalho tem como objetivo geral analisar os impactos da hospitalização e/ou atendimento ambulatorial hemodialítico ao processo de escolarização das crianças acometidas pela insuficiência renal crônica.

\section{Impactos da hospitalização e/ou atendimento ambulatorial hemodialítico ao processo de escolarização da criança com insuficiência renal crônica}

A insuficiência renal crônica pode causar grandes impactos à infância pela necessidade de atendimento ambulatorial ou internação no ambiente hospitalar, culturalmente antagônico ao desenvolvimento de uma infância saudável pelas submissões impostas no hospital (SIMÕES, 2016).

O cotidiano de um ser humano, em especial crianças e adolescentes diferencia-se, ao estar acometido por uma doença crônica, pelas suas implicações à vida social, pois ocasiona rupturas contextuais devido à necessidade constante de controle e de tratamento clínico em ambiente hospitalar. Assim, Grossman (2007) enfatizou que essas implicações acontecem pela manifestação de sintomas, hospitalização para exames, distanciamento dos familiares, do espaço escolar e limitações na locomoção.

Estas implicações geram instabilidade e, consequentemente, agravos ao processo de desenvolvimento da criança e à sua qualidade de vida, devido às exigências espaçotemporais próprias da enfermidade crônica. Este caráter ameaçador ocorre pelas limitações impostas pela patologia, que as impedem de prosseguir normalmente sua vida social. A criança precisa adequar-se, contraditoriamente, a um contexto que a estagna em prol de sua saúde (SIMÕES, 2016). 
http://dx.doi.org/10.5902/1984686X44360

Chiattone (2003), ao elencar os efeitos psicológicos causados pela hospitalização, em crianças enfatizou ansiedade, negação da doença, revolta, culpa, sensação de punição, projeção, depressão, solidão, frustração de sonhos e projetos, negativismo. Complementando esse pensamento, Calegari et al. (2009) afirmaram que o adoecimento causa, na maioria dos pacientes, algum grau de sofrimento, pois trata-se de um evento potencialmente traumático, o qual, devido a todas as implicações salientadas anteriormente, gera, também, 0 desenvolvimento de sentimentos de despersonalização, ansiedade, medo e insegurança.

Esses impactos emocionais, ocasionados pelo contexto hospitalar, causam na criança comprometimentos à sua vida social durante sua permanência no hospital e, em um póshospital, provocam desestímulos, com o risco de torná-la passiva às necessidades clínicas. Assim, são necessárias estratégias de enfrentamento da doença para que possa haver ressignificação de suas vivências no hospital e das rotinas anteriores, a exemplo, o brincar e o estudar (SIMÕES, 2016).

As estratégias de enfrentamento são caracterizadas como formas encontradas por profissionais inseridos no âmbito hospitalar ou mesmo pelas próprias crianças de alcançarem outras significações, que possam diferenciar-se e descentralizar-se do processo saúde-doença, ou seja, buscar vivências aparentemente perdidas ao adentrar no hospital (SIMÕES, 2016). Motta e Enumo (2004), ao falarem sobre estratégias de enfrentamento na hospitalização infantil e nos atendimentos ambulatoriais, apontam que o brincar contribui para que as crianças possam lidar melhor com as adversidades, reduzir o estresse e estimular uma adaptação positiva ao contexto em que estão inseridas.

As perdas oriundas do processo saúde-doença são significativas na vida da criança enferma. Dependendo do contexto que está inserida, seja pelo processo de hospitalização, seja pelos atendimentos ambulatoriais, as limitações intensificam-se e sobrepõem-se a outros direitos, a exemplo, a educação (SIMÕES, 2016). Considerando a Declaração dos Direitos da Criança, da Organização das Nações Unidas (1959, p. 2), " a criança gozará de proteção especial ser-lhe-ão proporcionadas oportunidades e facilidade por lei e por outros meios, a fim de lhe facultar o desenvolvimento físico, moral, espiritual e social, de forma sadia e normal e em condições de liberdade e dignidade".

Como enfatizado por Matos e Mugiatti (2011, p. 57): "se por direito, cabem à criança todas as forças facilitadoras do seu bem-estar, o livre acesso à saúde e educação, são direitos inalienáveis que requerem máxima proteção”. Destaca-se, nesse contexto, que: 
http://dx.doi.org/10.5902/1984686X44360

a criança hospitalizada é imersa em um ambiente que em nada lembra a vida que levava até esse momento. Uma das mais importantes perdas referentes a esse período é quando a criança encontra-se em idade escolar e precisa parar de frequentar a escola, de conviver com seus colegas e de realizar as tarefas a que ela estava acostumada. (SACCOL; FIGHERA; DORNELES, 2004, p.182)

Diante do contexto hospitalar, é natural as famílias preocuparem-se em garantir a saúde de seus filhos (as), considerando que vivenciam situações contraditórias ao contexto de inserção. Aparentemente não há como "estar hospitalizada" e "estar em processo escolar". Ambos necessitam de instituições diferenciadas e, normalmente, prioriza-se a saúde, independentemente do tempo que possa ser exigido, para posteriormente, retornar à escola (SIMÕES, 2016).

Assim, configura-se que a pessoa acometida por uma patologia crônica está inserida no hospital, sendo este um contexto contraditório e vulnerável. Apesar da educação e da saúde serem direitos inalienáveis de todos e assegurados legalmente pela Constituição Brasileira (BRASIL, 2016), anulam-se devido às incompatibilidades espaço-temporais, pois a escola e o hospital são espaços específicos, não sendo possível a pessoa com uma patologia crônica estar ao mesmo tempo em ambos. (SIMÕES, 2016).

Matos e Mugiatti (2011, p. 57) analisaram esse cenário como contraditório, quando há necessidade de hospitalizações prolongadas ou atendimentos múltiplos da criança do adolescente, afirmando que "tais direitos essenciais contraditoriamente se encontram na mais plena desproteção, diante do impasse com que se deparam: ou o tratamento, ou a escola, ou então, prejuízo de ambos; ou ainda acomodação ou conformismo".

Esse cenário torna-se comum, especialmente no contexto brasileiro, e o processo de escolarização de muitas crianças é comprometido, por não ser contemplado por estratégias que possam amenizar os impactos da hospitalização e dos atendimentos ambulatoriais (SIMÕES, 2016). O conformismo, caracterizado por Matos e Mugiatti (2011), pode ser considerado como reflexo de questões culturais, de modo que a doença é vista com grande estranhamento e negativismo, causando debilitação e mobilizando a pessoa a dedicar-se inteiramente ao quadro doentio.

Destacando-se o protagonismo das crianças no contexto hospitalar, tornam-se preocupantes as defasagens escolares ocasionadas pelo impedimento de retorno ao espaço escolar. Há, ainda, as que necessitam de atendimentos ambulatoriais semanalmente, comprometendo a frequência regular à escola (SIMÕES, 2016). O caráter de normalidade percebido no distanciamento da criança do espaço escolar, é coerente ao 
que Fonseca (2015) afirmou sobre a educação ser interpretada de maneira errônea no hospital como sendo exclusiva da escola, considerando que há também o pensamento de que o contato com conteúdos curriculares poderá levar a criança ao estresse, às debilitações física e mental. Em relação à possibilidade da escola no contexto hospitalar, afirmou:

tudo isso contribui para o estranhamento da presença da escola no ambiente hospitalar porque doença e internação para tratamento médico geralmente são vistas como ameaças à vida dando margem à desconfiança de que a morte também está presente em ambas as situações. Isso leva a pensar que o importante é curar a doença e o psicológico e o cognitivo do enfermo ficam para depois da cura. (FONSECA, 2015, p. 2)

Matos e Mugiatti (2011) enfatizaram que a situação escolar de crianças e adolescentes em tratamento de saúde é emergente, na medida em que o processo de escolarização é comprometido pelos longos períodos de submissão à hospitalização ou outros tratamentos, pela impossibilidade de continuarem e concluírem o ano letivo, assim como pela perda do vínculo escolar, ausência de matrículas, séries retrocedidas e índices de analfabetismo podendo alcançar a fase adulta. Dessa forma,

se por um lado o tratamento logra êxito, por outro o processo de escolaridade é quantitativa e qualitativamente prejudicado; em situação contrária o tratamento entra em colapso, com envolvimentos de gravidade muitas vezes irreversíveis. É o entrecruzamento de duas necessidades essenciais: ou a saúde, ou a educação, eis a contradição. (MATOS; MUGIATTI, 2011, p. 61),

A problemática da situação de crianças enfermas representa grandes defasagens escolares, evasões, desestímulos, bem como aumenta as taxas de analfabetismo (MATOS; MUGIATTI, 2011). Diante disso, a complexidade da relação entre educação/saúde, especificamente nas instituições escola/hospital, inicia-se e perpassa por antagonismos inseridos em questões espaço-temporais aparentemente excludentes: a criança que necessita estar na escola e, ao mesmo tempo, no hospital (SIMÕES, 2016). Corroborando com esse pensamento, "existe uma nítida contradição entre o necessário tratamento hospitalar e a necessária frequência escolar, uma vez que ambos exigem o mesmo espaço temporal" (MATOS; MUGIATTI, 2011, p. 60-61).

Referindo-se às crianças com insuficiência renal crônica, estes aspectos podem ser bem mais complexos e ir além da hospitalização, pois a permanência hospitalar ocorre, também, através dos atendimentos ambulatoriais, especialmente, a hemodiálise e, ainda que não estejam necessariamente hospitalizadas, podem acarretar grandes prejuízos à vida infantil e ao seu processo de escolarização pelas submissões impostas pela patologia. 
Tais prejuízos ocorrem por ser imprevisível o retorno dessas crianças ao contexto escolar, considerando que devido à cronicidade da IRC, as mesmas tornam-se dependentes do hospital, podendo ocasionar maiores déficits escolares ou mesmo a evasão escolar, conforme seu estado clínico. (SIMÕES, 2016)

Vieira e Lima (2002), buscando conhecer a experiência da criança, bem como as mudanças ocorridas em suas vidas, afirmaram que o cotidiano infantil é completamente modificado e relataram alguns aspectos referentes à escolarização. A respeito disso, tais autores foram bem enfáticos:

A escolarização e os relacionamentos sociais são também fatores importantes na etapa de desenvolvimento em que se encontram as crianças e os adolescentes do nosso estudo. A doença, a terapêutica e os efeitos colaterais dos medicamentos interferem na frequência às aulas, desmotivando-os e dificultando sua adaptação escolar. Eles sofrem discriminação dos colegas, seja pela superproteção dos professores, seja pela dificuldade de desenvolverem determinada atividade coletiva, sendo excluídos de algumas delas, pelos próprios colegas. Sentem-se diferentes, seu convívio social é limitado, tudo isso interferindo em sua autoestima. (VIEIRA; LIMA, 2002, p.559)

Diante disso, Vieira e Lima (2002) consideraram a escolarização como etapa de desenvolvimento, tendo em vista que a escola representa um espaço propício à inclusão escolar e as demandas da insuficiência renal crônica comprometem esse processo, pois interferem na frequência às aulas.

Ferreira et al. (2013), ao realizarem revisão de literatura a respeito do cuidado à criança com insuficiência renal, afirmaram que a patologia apresenta implicações nos desenvolvimentos físico, mental e emocional, cujos cotidianos são modificados por restrições provocadas pela patologia.

Essas restrições influenciam diretamente toda a vida da criança, sobretudo o processo de escolarização, pois, comprometidas fisicamente, mentalmente e emocionalmente, os impactos da hospitalização e do atendimento ambulatorial hemodialítico tendem a ser mais agressivos e trazer maiores comprometimentos à educação dessas crianças.

Para Frota et al. (2010), apesar das necessidades pessoais e educacionais das crianças não serem totalmente atendidas, as ressignificações realizadas por elas apontam amenização dos impactos causados pela hospitalização e/ou pelo atendimento ambulatorial hemodialítico. Assim, a pesquisa dos autores mostrou que, por haver estratégias de enfrentamento da doença, os impactos provenientes do contexto hospitalar 
http://dx.doi.org/10.5902/1984686X44360

não superam a possibilidade dessas crianças serem felizes e sentirem-se bem, alcançando qualidade de vida satisfatória.

Bizarro (2001, p. 57), ao analisar o bem-estar psicológico de adolescentes com insuficiência renal crônica, apontou consequências desfavoráveis oriundas dos impactos da hospitalização e/ou do atendimento ambulatorial hemodialítico, afirmando que: "alterações ao bem-estar psicológico podem ser os precursores de todo um espectro de desordens psicológicas mais graves que podem surgir de numerosas formas, desde problemas comportamentais e emocionais, ao insucesso escolar".

Amorim (2014) estudou a escolarização de crianças e adolescentes em hemodiálise, considerando os longos períodos no contexto hospitalar, com objetivo de investigar os significados do processo de escolarização para crianças e adolescentes com insuficiência renal crônica que realizavam hemodiálise em um hospital público de Salvador-BA. Identificou que para essas pessoas a escolarização no contexto da IRC e da hemodiálise pressupõe:

a adaptação à realidade da forma como esta se apresenta, quer seja na escola comum ou na classe hospitalar, não sendo possível falar da educação escolar destas pessoas, sem antes perceber o peso marcado pela doença em suas vidas e as dificuldades e possibilidades encontradas em seus percursos carregados de emoções em seus cuidados, privações e rearranjos que, por vezes, são necessários nos inesperados de suas trajetórias existenciais. (AMORIM, 2014, p. 8)

As considerações de Amorim (2014, p. 8) preveem significados aplicados à escolarização, articulados à experiência de vida dos participantes da pesquisa, em meio às dificuldades e possibilidades, a partir das imposições da patologia, destacando a importância de conhecer as necessidades dessas crianças e adolescentes, para "garantir a assistência plena em saúde, educação e seu processo de inclusão".

A pesquisa de Pennafort (2010) retratou as dificuldades de continuidade dos estudos como uma das maiores problemáticas relatadas. Assim, destaca que a escola foi deixada por vários motivos:

porque não conseguiram acompanhar as aulas em razão dos horários do tratamento, internações, mudança de cidade, e até pela não-aceitação dos colégios após o adoecimento renal. Às vezes a própria casa e a família ficaram pra trás, e a convivência com parentes, que até então mal conheciam se tornou necessária, dificultando mais ainda a adaptação à terapêutica dialítica. (PENNAFORT, 2010, p. 14)

Diante dos resultados das pesquisas destacadas, são apontadas diversas problemáticas referentes ao processo de escolarização de crianças e adolescentes com 
http://dx.doi.org/10.5902/1984686X44360

IRC, dentre elas, o insucesso escolar, a evasão escolar, as dificuldades de acompanhamento curricular, a baixa frequência escolar e o analfabetismo (SIMÕES, 2016).

Normalmente, a escolarização é retratada de forma mais superficial, destacando-se as necessidades educacionais dessas pessoas no contexto hospitalar. A visibilidade das crianças acometidas pela IRC, nos contextos educacional e social, mostra-se comprometida e seu acolhimento tem sido melhor abordado quanto às questões clínicas e psíquicas, apontando desarticulação entre educação e saúde. Assim, aponta-se a necessidade de um olhar específico à realidade escolar dessas crianças, bem como as implicações e comprometimentos ao processo de escolarização causados pelo tratamento de saúde. (SIMÕES, 2016)

\section{Metodologia}

A pesquisa foi realizada em duas das unidades de atendimento de um hospital público federal, em São Luís-MA, sendo aprovada pelo Comitê de Ética em Pesquisa, envolvendo Seres Humanos do Hospital Universitário da UFMA, com o parecer consubstanciado $\mathrm{n}^{\circ}$ 1.522.437 de 29/04/2016. Desta forma, a escolha por estas unidades de atendimento ocorreu por atenderem o público infantil em processo de hospitalização e/ou de atendimento ambulatorial hemodialítico, ocasionado pela insuficiência renal crônica.

Tratou-se de uma pesquisa do tipo quanti-qualitativa, descritiva, sob a forma de múltiplos casos, com 10 crianças, sendo 3 hospitalizadas, 6 em atendimento ambulatorial hemodialítico e 1 hospitalizada em enfermaria pediátrica e, paralelamente, realizando hemodiálise; 50\% eram meninos e 50\% meninas; com faixas etárias variando entre 8 a 12 anos de idade; $90 \%$ das crianças adquiriram a insuficiência renal crônica e 10\% acometidas pela enfermidade desde a gestação de sua mãe; $90 \%$ eram oriundas de interiores do Maranhão e somente $10 \%$ eram da capital maranhense.

Como a maioria das crianças era do interior da capital, $80 \%$ não frequentavam a escola e $20 \%$ frequentavam com limitações. Como enfatizaram Matos e Mugiatti (2011), os dados correspondentes a este tipo de realidade são compatíveis às vivências e ao estado clínico da saúde de cada criança. Percebeu-se que a criança, para apresentar defasagens escolares, não precisava estar necessariamente hospitalizada. Os autores apontaram que os atendimentos ambulatoriais intermitentes também ocasionaram impactos ao processo de escolarização pelas especificidades da patologia, destacando a evasão escolar, prejuízos e atrasos. 
http://dx.doi.org/10.5902/1984686X44360

As crianças pesquisadas cursavam da $1^{\text {a }}$ série $/ 2^{\circ}$ ano a $4^{\text {a }}$ série $/ 5^{\circ}$ ano do Ensino Fundamental, porém com idades cronológicas não compatíveis às etapas de escolarização, indicando possibilidade de atrasos escolares, pois deveriam estar em séries entre $3^{\circ}$ ano ao $7^{\circ}$ ano do Ensino Fundamental, caso houvesse regularidade escolar. Como afirmaram Matos e Mugiatti (2011), os atrasos escolares são constantes até mesmo para as crianças que estão em atendimento ambulatorial pela necessidade frequente do tratamento.

A identificação das crianças foi organizada por letra alfabética e codinomes, a fim de resguardar a identidade destas, em cumprimento à Resolução MS/CNS 466/2012, do Conselho Nacional de Saúde. Dessa forma, cada criança teve a letra alfabética associada ao codinome: Criança A - O Pequeno Príncipe; Criança B - Sorriso; Criança C - Esmeralda; Criança D - Valente; Criança E - Pérola; Criança F - Vitório; Criança G - Jasmin; Criança H - Apolo; Criança I - Estrela e Criança J - Luna.

As entrevistas semiestruturadas com as crianças foram realizadas individualmente em dois ambientes: nos respectivos leitos das enfermarias pediátricas, com aquelas hospitalizadas e, na sala de hemodiálise, com as submetidas a esse tratamento, sendo gravadas e registradas com a utilização de recursos lúdicos, como a história interativa, o livro autobiográfico e a caixa dos desejos, para proporcionar momentos agradáveis às crianças pesquisadas e significativos ao seu contexto.

De acordo com Santos (2009, p. 6) "as histórias infantis podem funcionar como verdadeiro remédio para a alma". A criança, assim, distancia-se um pouco do sofrimento pelo qual está passando, colocando sua imaginação e criatividade em desenvolvimento, contribuindo com a sua evolução cognitiva e facilitando sua aceitação perante seu estado de saúde.

Todas as entrevistas iniciaram-se com a contação da história interativa, criada e proposta pelas pesquisadoras, denominada "Os irmãos colecionadores de histórias". Esta história foi toda ilustrada em formato de livro didático e apresentada às crianças com o uso de um tablet com apoio.

A história interativa apresentou as vivências de dois irmãos, que necessitavam deslocar-se constantemente de uma cidade para outra, devido às mudanças de seus pais em seus respectivos empregos. Esses deslocamentos os obrigavam, consequentemente, a estarem em vários lugares em pouco espaço de tempo, tendo de afastar-se da escola, dos amigos, do restante da família e de tudo que realizavam e gostavam na cidade de origem. Tal história foi pensada para que as crianças com IRC se identificassem com as 
vivências dos personagens, permitindo uma reflexão acerca da realidade em que estavam inseridas no hospital. Ressalta-se que algumas das crianças pesquisadas necessitavam residir em São Luís, fato que favorecia seus tratamentos, enquanto que outras submetiamse a uma rotina de constantes idas e vindas de suas cidades de origem localizadas em interiores maranhenses distantes da capital São Luís para tratamento de saúde (SIMÕES, 2016).

A partir dessa história interativa foi aplicado o roteiro de entrevista semiestruturada com cada criança pesquisada. Concomitantemente às perguntas, as crianças confeccionaram um livro autobiográfico com desenhos e pinturas, no qual representavam a si mesmas, o hospital, a escola e sua família/casa.

Ao final, os maiores desejos das crianças foram colocados na caixa dos desejos, na qual as crianças expressaram-se através de pequenos bilhetes ou desenhos. Ao depositálos nessa caixa, tais bilhetes foram escritos por elas ou ditados por elas e escritos pelas pesquisadoras, apontando seus principais desejos referentes ao hospital, à escola e a sua casa/família.

Após o término da coleta de dados, a próxima etapa consistiu na escuta e transcrição das entrevistas, em um primeiro momento. No segundo momento, a escuta da entrevista foi analisada e categorizada em consonância com os desenhos realizados pelas crianças, assim como seus bilhetes, no intuito de resgatar o máximo possível do que foi expresso em seu decorrer, estabelecendo categorias de análise para um estudo mais profundado dos dados obtidos na coleta.

Em relação aos critérios de análise das entrevistas, após transcrição das mesmas, foi utilizada a técnica de análise proposta por Bardin (1977). Segundo a autora, "a análise de conteúdo pode ser considerada como um conjunto de técnicas de análises de comunicações, que utiliza procedimentos sistemáticos e objetivos de descrição do conteúdo das mensagens" (BARDIN, 1977, p.38).

\section{Resultados e discussão}

Verificou-se que $90 \%$ das crianças afirmaram sentir-se prejudicadas nos estudos pela hospitalização e/ou tratamento de saúde pela hemodiálise, associando esses prejuízos a motivos específicos. As categorias manifestadas compreenderam: atrasos escolares e comprometimentos futuros pela impossibilidade de frequência escolar (60\%); perda do vínculo escolar pela distância entre hospital e escola (20\%); ausência de recursos 
http://dx.doi.org/10.5902/1984686X44360

apropriados à escolarização no hospital (10\%); dificuldades de realizar matrícula em escola próxima de casa (10\%); e uma criança não respondeu (10\%), correspondendo à criança $\mathrm{J}$.

A maioria das crianças, correspondendo a $60 \%$ (crianças $A, C, D, G, H, I$ ), associou os impactos aos atrasos escolares e comprometimentos futuros pela impossibilidade de frequência escolar, como pode ser destacado em algumas falas:

CRIANÇA D: Uhum, um pouco. Porque é a única vez que eu 'tô' internado, as outras vezes era só 'pra' consulta mesmo. Já internei aqui 'duas vezes', uma pra fazer a biópsia e essa. Porque eu tô perdendo o ano, aí é mais difícil até pra eu me formar em alguma coisa.

CRIANÇA I: Prejudica. É porque eu acabo esquecendo das 'coisas'. Eu só sei escrever. Escrever eu sei, botar as coisas certinha, ler não. É...eu já tava tudinho certinho, o que aconteceu é porque eu comecei a fazer hemodiálise, acabei esquecendo a memória, ficou fraca a memória. Porque eu não leio mais, fica difícil...aí eu sempre quero estudar.

A Criança A destacou a necessidade de estar no hospital, as perdas das aulas e do ano letivo, remetendo sua percepção à discussão bem peculiar na defesa dos direitos da criança hospitalizada. A Criança $\boldsymbol{D}$ não sentia tanto, ainda, a perda do vínculo escolar, pois a hospitalização, em 2016, foi a segunda mais longa desde a descoberta da insuficiência renal crônica. Como tinha histórico de repetência escolar, afirmou que estava perdendo o ano letivo, sendo um agravante para o alcance de sua formação futura.

As perspectivas de vida representaram preocupações nas falas de algumas crianças, pois reconheciam os estudos como oportunidade de crescimento. A ausência da escola, acrescida dos atrasos escolares, geraria consequentes dificuldades na própria vida das crianças (SIMÕES, 2016).

A visão prevalecente, ainda, em sociedade é da contradição espaço-temporal, como afirmaram as Crianças $\boldsymbol{G}$ e $\boldsymbol{H}_{s}$ associando os motivos à hemodiálise, seja pela interrupção ao processo de escolarização, seja pela pouca frequência escolar. Não há como estar presente em dois lugares e, nessas circunstâncias, a saúde prevalece. Esse pensamento é prejudicial à própria criança, pois, ainda que tenha consciência dos prejuízos causados, a patologia pode ser vista como determinante em suas vidas, ocultando o direito de receber 0 atendimento educacional pedagógico hospitalar (MATOS; MUGIATTI, 2011).

Concorda-se com Pennafort, Queiroz e Jorge (2012) que a permanência das crianças com insuficiência renal crônica para tratamento da saúde, por longos períodos de tempo, está relacionada à gravidade dessa patologia e que essas defasagens escolares serão maiores pela impossibilidade de frequência escolar, podendo mesmo comprometer o futuro dessas crianças. Esses aspectos foram confirmados nesta pesquisa, considerando que a 
http://dx.doi.org/10.5902/1984686X44360

maioria (60\%) das crianças entrevistadas relatou atrasos escolares e comprometimentos futuros pela impossibilidade de frequência escolar como impactos provenientes da hospitalização e/ou do atendimento ambulatorial hemodialítico ao processo de escolarização de crianças com insuficiência renal crônica.

Outra categoria apresentada foi a perda do vínculo escolar pela distância da escola (20\%), apontada pelas crianças B e $\boldsymbol{E}$, sendo estes motivos de preocupação para as crianças, conforme suas falas:

CRIANÇA B: Sim. Por que... De que forma? É... porque a gente... a gente aqui vai pegando manha de ficar deitado, ai quando chegar lá não vai querer ir pra escola, vai querer ficar deitado também, aí a gente esquece as coisas. Pelo tempo que fica aqui...aí vai chegando a manha. Porque esse tempo que eu fico aqui, eu num dou pra mim escrever, fazer as coisas, fico só assistindo, o Chaves.

CRIANÇA E: Porque é ruim da... dá saudade da casa. Atrapalha, porque eu fico fazendo hemodiálise.

A perda do vínculo escolar, relatada desta vez pelas Crianças $\boldsymbol{B}$ e $\boldsymbol{E}$, ocorria pelo tempo de permanência das mesmas em contexto hospitalar, pois tal rotina diferenciava-se da escolar e as atividades curriculares eram substituídas por outras de cunho terapêutico. Assim, revelaram que o tempo ocioso no hospital e a distância da escola comprometiam o que já foi aprendido, gerando esquecimentos. Tal perda está vinculada às grandes defasagens escolares, evasões, desestímulo, aumento das taxas de analfabetismo, que representam a situação de crianças enfermas (MATOS; MUGIATTI, 2011).

Reforçando a resposta de perda do vínculo escolar pela distância entre hospital/escola, relatada por $20 \%$ das crianças pesquisadas, Vieira, Dupas e Ferreira (2009) ressaltaram que as crianças com insuficiência renal crônica necessitam de controle a longo prazo e podem apresentar limitações de suas atividades rotineiras pelas exigências de seu tratamento. Dessa forma, a IRC altera a qualidade de vida infantil, sobretudo, o cotidiano escolar, pois gera a perda do vínculo com a escola, devido as demandas terapêuticas, do controle clínico e das hospitalizações recorrentes.

Ressalta-se, ainda, que, como $90 \%$ são oriundas de cidades do interior do Maranhão e o tratamento era realizado na capital São Luís, a distância entre hospital e escola favoreceu essa perda do vínculo escolar.

Outro impacto relatado compreendeu a ausência de recursos apropriados à escolarização no hospital, correspondendo a 10\% das crianças participantes, informado pela Criança $\boldsymbol{C}$, enfatizando: “É. Porque não tem cadeira...é longe”. O único espaço, no hospital, que permitia a aproximação com a estrutura escolar, era a brinquedoteca 
hospitalar, mobiliada por quadro branco, cadeiras, mesas, brinquedos e recursos didáticos como: livros, lápis, cadernos e demais materiais. No entanto, tratava-se de um espaço bem pequeno, localizado na enfermaria pediátrica, e as atividades propostas nesse ambiente, ainda, eram realizadas com limitações. A escola, muitas vezes, é improvisada no contexto hospitalar por questões culturais, as quais consideram o processo saúde-doença como algo predominantemente negativo, como enfatizado por Fonseca (2015).

A Criança I apontou a categoria dificuldades de realizar matrícula (10\%), demonstrando insatisfação pelo desejo de estudar, o que não era possível no momento. Devido ao distanciamento da escola, a criança apresentava limitações e comprometimentos na leitura, apontados por ela como: não saber mais ler e escrever algumas coisas e a necessidade de pedir ajuda à mãe quando precisava de algo relacionado à escrita e à leitura.

Constatam-se, assim, os sérios comprometimentos que atingiam as crianças submetidas à hemodiálise, assim como as hospitalizadas, conforme a seguinte fala: "Aí a mãe tentou achar vaga, vaga....nunca achou a vaga pro colégio. É... e ela nunca acha. Lá pro bairro que nós 'tamo'. Tem uma lá, mas é a parte de... é pra 'pequenozinho'. É pequeno, aqueles de três anos a seis anos" (CRIANÇA I).

As idas à escola pelas crianças em hemodiálise tornam-se escassas, ou até mesmo impossíveis, com as demandas do tratamento da insuficiência renal crônica, mesmo não estando em regime de internação. Assim, os impactos ao processo de escolarização podem ser maiores, dependendo do contexto de cada uma. Matos e Mugiatti (2011) relataram que a hospitalização e/ou atendimento ambulatorial em multiplicidade ocasionam dificuldades de matrícula, analfabetismo, bem como conformismo diante das limitações impostas pelo hospital, como bem retratado pela Criança I.

Dando maior visibilidade aos contextos diferenciados, o hospital e a escola, infere-se que os impactos ao processo de escolarização são maiores e variáveis, mas não anulam a importância sentida pelas crianças dessa fase tão importante como é a etapa escolar na infância.

Conhecendo as vivências das crianças com insuficiência renal crônica e suas experiências no hospital e/ou no atendimento ambulatorial hemodialítico, perceberam-se muitos desafios enfrentados por elas para a continuidade de seus estudos e no desejo em "serem crianças". A partir dessa aproximação ao contexto vivenciado, foi possível estabelecer que os impactos do processo de escolarização causados pela insuficiência 
renal crônica não ocorrem necessariamente apenas pela hospitalização, mas também através da hemodiálise, que se trata de um atendimento ambulatorial, influenciando as perspectivas e expectativas de vida das crianças pesquisadas (AMORIM, 2014).

Além de toda a problemática causada pelo tratamento hospitalar e/ou atendimento ambulatorial para realização da hemodiálise, a Criança I ressaltou a falta de escolas para crianças acima de 6 anos como um impasse bastante frequente tanto em determinadas regiões do interior do Maranhão quanto na própria capital, sendo mais um indicador responsável pelos atrasos escolares e até mesmo pela evasão escolar, independentemente de as crianças estarem ou não em tratamento de saúde.

Dessa forma, enfatiza-se também as limitações causadas pela localização geográfica das escolas em relação às residências das crianças, como destacado pela Criança I, que dificultam mais ainda a possibilidade de continuidade aos estudos, pois os deslocamentos tornam-se debilitantes para a realização da hemodiálise e as escolas distantes duplicam o desgaste físico, podendo também comprometer a saúde da criança. Assim, isso reflete a carência de ações sistematizadas para inclusão desses estudantes no ensino público, que possam viabilizar o acesso à educação.

O processo de escolarização era visto com saudade por grande parte das crianças, como algo que só aconteceria, através da recuperação total da patologia, no futuro. No entanto, a cronicidade pode ser bem limitante pela indeterminação que acarreta à vida e, na maioria das vezes, com agravantes irreversíveis. Então, depender da total recuperação de uma doença crônica pode ser considerado bem ameaçador à atenção integral dessas crianças pela sua imprevisibilidade e pela necessidade constante de estar no espaço hospitalar (AMORIM, 2014; PENNAFORT, 2010).

Nas falas das crianças, verificou-se parte da realidade de cada uma, mostrando contradições às demais infâncias pelas privações que lhes acometem. Foi muito comum a preocupação prioritária à saúde. Normalmente, é um eixo social visto em primeiro plano, para que se possa exercer as demais atividades e funções cotidianas. No entanto, compreender a educação como parte intrínseca do ser humano e colaboradora até mesmo ao quadro clínico da criança torna-se mais complexo, por serem os contextos hospitalar, ambulatorial e o escolar vistos como antagônicos. 
http://dx.doi.org/10.5902/1984686X44360

\section{Considerações finais}

Sabe-se que crianças acometidas por uma patologia crônica vivem uma infância diferenciada pelas peculiaridades e singularidades que envolvem o "estar doente". A necessidade constante de tratamento de saúde acarreta muitas imposições à vida da criança e os seus direitos ficam vulneráveis, sobretudo, os educacionais.

Aparentemente as crianças com insuficiência renal crônica vivem uma contradição, pois não há como estar na escola e no contexto hospitalar. Porém, considerando a educação como direito constitucional, eis uma dupla contradição, pois a mesma é um direito de todos e deve ser garantida, mesmo em contexto hospitalar, no qual se incluem os espaços ambulatoriais que realizam atendimentos de longa duração, como a hemodiálise, por exemplo.

No entanto, a visão tradicional da dissociabilidade hospital e escola como instituições com fins específicos faz com que educação e saúde sigam desarticuladas, desconsiderando a escolarização dessas crianças, por não haver atendimentos efetivos que supram essa necessidade.

As crianças, que necessitavam dos dois processos, relataram longos períodos ausentes da escola pela impossibilidade de realizar o tratamento de saúde na cidade de origem, sendo esta situação a que acarretou o maior índice de evasão e/ou frequência irregular à escola pelas crianças em hemodiálise, devido à constância no tratamento e deslocamentos desgastantes à capital São Luís.

Dessa forma, os maiores impactos da hospitalização e/ou atendimento ambulatorial hemodialítico ao processo de escolarização de crianças com insuficiência renal crônica foram atrasos escolares e comprometimentos futuros pela impossibilidade de frequência escolar; perda do vínculo escolar pela distância entre hospital/escola; ausência de recursos apropriados à escolarização no hospital e dificuldades de realizar matrícula em escola próxima de casa. Ressalta-se, ainda, a problemática da inexistência de escolas próximas ao local de residência das crianças com IRC, sobretudo, nas cidades do interior do Maranhão e, quando presentes, destinavam-se ao atendimento de crianças na faixa de idade entre 3 e 6 anos.

É importante enfatizar que, para as crianças que moram na cidade de São Luís, o fato de não conseguirem a matrícula em escolas próximas de sua casa reflete na carência de uma sistematização de ações que possa atender o contexto peculiar dos estudantes em tratamento de saúde, tendo em vista que os constantes deslocamentos para a realização 
de hemodiálise já causam grandes debilitações físicas, que fragilizam não só o processo de escolarização devido às questões espaço-temporais, mas a criança em si, em seus aspectos emocionais e sociais. Dessa forma, é imprescindível um olhar mais atento a essas crianças para que possam ser efetivamente incluídas educacionalmente e enquanto pessoas de direito.

Concluiu-se que os maiores impactos à escolarização foram manifestados pelas crianças em tratamento hemodialítico, por ser um processo contínuo, imprevisível e indeterminado, demandando maiores privações do contexto escolar ou mesmo ausências, variando de cinco meses a quatro anos, ocasionando maiores déficits e comprometendo a vida escolar.

Os resultados desta pesquisa confirmaram a necessidade da criação de ações, as quais possam concretizar e efetivar integralmente e não apenas condicionalmente o atendimento educacional hospitalar, estreitando os laços entre educação e saúde, de maneira que possam contribuir com a mediação entre a criança, a escola, a família e o hospital.

Diante disso, a pesquisa aponta caminhos importantes a serem trilhados na realidade maranhense, no que diz respeito a algumas questões pertinentes como: ampliação de estudos relacionados ao atendimento educacional hospitalar, efetivação de classes hospitalares em ambientes públicos e particulares de tratamento de saúde, articulações intersetoriais voltadas para a formação continuada de professores na perspectiva inclusiva no processo de escolarização das crianças com IRC e também a conscientização das famílias e sociedade sobre o direito à educação às crianças em situação de agravamento das condições de saúde.

\section{Referências}

AMORIM, Priscila Santos. Significados da escolarização para crianças/adolescentes com insuficiência renal crônica na vivência com a hemodiálise. 2014. 204 f.

Dissertação (Mestrado em Educação) - Faculdade de Educação, Universidade Federal da Bahia, Salvador, 2014.

BARBOSA, Maria Carmem Silveira; DELGADO, Ana Cristina Coll; TOMÁS, Catarina Almeida. Estudos da infância, estudos da criança: Quais campos? Quais teorias? Quais questões? Quais métodos? Inter-Ação, Goiânia, v.41, n.1, p. 103-122, jan. /abr.2016.

BARDIN, Laurence. Análise de conteúdo. Tradução Luís Antero Reto, Augusto Pinheiro. Lisboa: Edições 70, 1977. 
BIZARRO, Luísa. O bem-estar psicológico de adolescentes com insuficiência renal crônica. Psicologia, Saúde \& Doenças, Lisboa, v. 2, n. 2, p. 55-67, 2001.

BRASIL. [Constituição (1988)]. Constituição da República Federativa do Brasil de 1988. Brasília, DF: Presidência da República, [2016]. Disponível em:

http://www.planalto.gov.br/ccivil_03/Constituicao/Constituiçao.htm. Acesso em: 10 mar. 2020.

BRASIL. Decreto no 7.611, de 17 de novembro de 2011. Dispõe sobre a educação especial, o atendimento educacional especializado e dá outras providências. Diário Oficial da União: seção 1, Brasília, DF, 18 nov. 2011. Disponível em: http://www.planalto.gov.br/ccivil_03/_ato2011-2014/2011/decreto/d7611.htm. Acesso em: 10 mar. 2020.

BRASIL. Lei nำ 13.716, de 24 de setembro de 2018. Altera a Lei $n \div 09.394$, de 20 de dezembro de 1996 (Lei de Diretrizes e Bases da Educação Nacional), para assegurar atendimento educacional ao aluno da educação básica internado para tratamento de saúde em regime hospitalar ou domiciliar por tempo prolongado. Diário Oficial da União: seção 1, Brasília, DF, 25 set. 2018. Disponível em: http://www.planalto.gov.br/ccivil_03/_Ato2015-2018/2018/Lei/L13716.htm. Acesso em: 10 mar. 2020.

BRASIL. Ministério da Educação. Conselho Nacional de Educação. Câmara de Educação Básica. Resolução CNE/CEB nํ4, de 2 de outubro de 2009. Institui Diretrizes Operacionais para o Atendimento Educacional Especializado na Educação Básica, modalidade Educação Especial. Diário Oficial da União: seção 1, Brasília, DF, p. 17, 5 out. 2009.

BRASIL. Ministério da Educação. Secretaria de Educação Especial. Grupo de Trabalho da Política Nacional de Educação Especial. Política Nacional de Educação Especial na Perspectiva da Educação Inclusiva. Brasília, DF: Ministério da Educação, 2008. Disponível em: http://portal.mec.gov.br/arquivos/pdf/politicaeducespecial.pdf. Acesso em: 10 mar. 2020.

CALEGARI, Rita de Cássia. et al. Instrumento de classificação da complexidade emocional dos pacientes internados em hospital geral: relato de experiência. Psicologia para América Latina, México, n. 18, nov. 2009.

CHIATTONE, Heloisa Benevides de Carvalho. Prática hospitalar. In: ENCONTRO NACIONAL DE PSICÓLOGOS DA ÁREA HOSPITALAR, 8. 2003, São Paulo. Anais [...]. São Paulo: Associação Brasileira de Psicologia da Saúde e Hospitalar, 2003. p. 20-32.

CONSELHO NACIONAL DOS DIREITOS DA CRIANÇA E DO ADOLESCENTE. Resolução no 41, de 13 de outubro de 1995. Aprova em sua íntegra o texto oriundo da Sociedade Brasileira de Pediatria, relativo aos Direitos da Criança e do Adolescente Hospitalizados. Diário Oficial da União: seção 1, Brasília, DF, p. 16.319-16.320, 17 out. 1995.

DRAGO, Rogério. Inclusão na educação infantil. Rio de Janeiro: Wak, 2011. 
FERREIRA, Maria José Alves da Silva et al. O cuidado à criança com insuficiência renal: uma revisão integrativa da literatura. Cadernos de Graduação - Ciências Biológicas e da Saúde Facipe, Recife, v. 1, n. 1, p. 37-149, 2013.

FONSECA, Eneida Simões. Classe hospitalar e atendimento escolar domiciliar: direito de crianças e adolescentes doentes. Revista Educação e Políticas em Debate, Rio de Janeiro, v. 4, n. 1, p. 12-28, jan./jul. 2015.

FROTA, Mirna Albuquerque. et al. Qualidade de vida da criança com insuficiência renal crônica. Escola Anna Nery, Rio de Janeiro, v. 14, n. 3, p. 527-533, 2010.

GIL, Antonio Carlos. Como elaborar projetos de pesquisa. 5. ed. São Paulo: Atlas, 2010.

GROSSMAN, Eloísa. Casos crônicos: quando é preciso aprender a conviver com a doença. In: KAPLAN, S. (coord.). Conversando sobre saúde com adolescentes. Rio de Janeiro: Instituto Ciência Hoje, 2007. (Ciência Hoje na Escola, 13). p. 68-71.

MATOS, Elizete Lúcia Moreira; MUGIATTI, Margarida Moreira Teixeira de Freitas.

Pedagogia hospitalar: a humanização integrando educação e saúde. 7. ed. Petrópolis: Vozes, 2011.

MOTTA, Alessandra Brunoro; ENUMO, Sônia Regina Fiorim. Brincar no hospital: estratégia de enfrentamento da hospitalização infantil. Psicologia em Estudo, Maringá, v.9, n. 1, p. 19-28, jan./abr. 2004.

\section{ORGANIZAÇÃO DAS NAÇÕES UNIDAS. Declaração dos Direitos da Criança.}

[Genebra]: ONU, 1959. Disponível em:

http://www.direitoshumanos.usp.br/index.php/Crian\%C3\%A7a/declaracao-dos-direitos-dacrianca.html. Acesso em: 23 out. 2015.

PENNAFORT, Viviane dos Santos. Crianças e adolescentes em tratamento dialítico: aproximações com o cuidado cultural da enfermagem. 2010. 138 f. Dissertação (Mestrado em Cuidados Clínicos em Saúde) - Universidade Estadual do Ceará, Fortaleza, 2010.

PENNAFORT, Viviane dos Santos; QUEIROZ, Maria Veraci Oliveira; JORGE, Maria Salete Bessa. Crianças e adolescentes renais crônicos em espaço educativo-terapêutico: subsídios para o cuidado cultural de enfermagem. Revista da Escola de Enfermagem da USP, São Paulo, v.46, n.5, p. 1057-1065, out. 2012.

PÉREZ-RAMOS, Aidyl Macedo de Queiroz. O ambiente na vida da criança hospitalizada. In: BOMTEMPO, E. G.; ANTUNHA, E. G.; OLIVEIRA, V. B. Brincando na escola, no hospital, na rua... Rio de Janeiro: Wak Editora, 2008. p.111-126.

PICCININI, Cesar Augusto et al. A doença crônica orgânica na infância e as práticas educativas maternas. Estudos de Psicologia, Natal, v. 8, n.1, p. 75-83, 2003. 
http://dx.doi.org/10.5902/1984686X44360

RABELO, Francy Sousa. Educação não escolar e saberes docentes na formação do pedagogo: análise de uma experiência no espaço hospitalar. 2014.184f. Dissertação (Mestrado em Educação) - Centro de Educação, Universidade Estadual do Ceará, Fortaleza, 2014.

SACCOL, Camila Sousa; FIGHERA, Jossiele; DORNELES, Letícia. Hospitalização infantil e educação: caminhos possíveis para a criança doente. Revista Vidya, Santa Maria, v. 24, n. 42, p. 181-190, 2004.

SANTOS, Thiala Conceição. Literatura na hospitalização infantil: um remédio para alma. 2009. 66 f. Monografia (Curso de Pedagogia) - Universidade Federal da Bahia, Salvador, 2009.

SIMÕES, Karina Cristina Rabelo. Vozes à infância silenciada: impactos da hospitalização e/ou atendimento ambulatorial hemodialítico ao processo de escolarização de crianças com insuficiência renal crônica. 2016. 264 f. Dissertação (Mestrado em Educação) - Centro de Ciências Sociais, Universidade Federal do Maranhão, São Luís, 2016.

VIEIRA, Maria Aparecida; LIMA, Regina Aparecida Garcia de. Crianças e adolescentes com doença crônica: convivendo com mudanças. Revista Latino-Americana de Enfermagem, Ribeirão Preto, v. 10, n. 4, p. 52-60, 2002.

VIEIRA, Sheila de Souza; DUPAS, Giselle; FERREIRA, Noeli Marchioro Liston Andrade. Doença renal crônica: conhecendo a experiência da criança. Escola Anna Nery, Rio de Janeiro, v. 13, n. 1, p. 74-83, 2009.

\section{Correspondência}

Karina Rabelo Simões - Secretaria Municipal de Educação, SEMED, Av.Castelo Branco, 250 - São Francisco, São Luís - MA

CEP: 65076-090

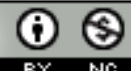

This work is licensed under a Creative Commons Attribution-NonCommercial 4.0 International (CC BY-NC 4.0) 